\title{
Tracheobronchoscopic Evaluation of Bacterial Pneumonia in Cattle
}

\author{
E. Venkatesakumar ${ }^{*}$, G. Vijayakumar ${ }^{1}$, G.A. Balasubramaniam² and J. Johnson Rajeswar ${ }^{3}$ \\ ${ }^{1}$ Department of Veterinary Clinical Medicine, Veterinary College and Research Institute, Namakkal, Tamilnadu Veterinary and \\ Animal Sciences University, Chennai, Tamil Nadu, INDIA \\ ${ }^{2}$ Department of Veterinary Pathology, Veterinary College and Research Institute, Namakkal, Tamilnadu Veterinary and Animal \\ Sciences University, Chennai, Tamil Nadu, INDIA \\ ${ }^{3}$ Department of Veterinary Microbiology, Veterinary College and Research Institute, Tirunelveli, Tamilnadu Veterinary and \\ Animal Sciences University, Chennai, Tamil Nadu, INDIA \\ "Corresponding author: E Venkatesakumar; E-mail:drvenkat75@gmail.com
}

Received: 8 April, 2020

Revised: 21 April, 2020

Accepted: 22 April, 2020

\begin{abstract}
Seventy two cattle with bacterial pneumonia and twelve healthy cattle were studied in detail for haemato-biochemical examination, radiography and tracheobronchoscopy. Haematobiochemical examination revealed leukocytosis with neutrophilia. Radiographic examination showed increased pulmonary infiltration. Tracheobronchoscopic examination of affected animals revealed inflammation, haemorrhage, mucus to mucopurulent exudates in nasal cavity, trachea, bronchi and bronchioles. Bronchoalveolar lavage (BAL) collected through endoscope was subjected to cytology and cultural examination. Cytology of the affected animals showed increased total cell counts and predominant neutrophils. Pasteurella multocida, Pseudomonas aeruginosa, Klebsiella pneumoniae and Escherichia coli were isolated from BAL and confirmed with PCR studies.
\end{abstract}

Keywords: Tracheobronchoscopy, Pneumonia, Cattle, Bronchoalveolar lavage, Cytology, PCR

Pneumonia is one of the important diseases affecting cattle causing severe economic loss to the dairy industry in India. Cattle are more prone for pneumonia due to small physiological gaseous exchange capacity and resultant basal ventilatory activity, increased compartmentalization and reduced alveolar macrophages activity leading to impaired pulmonary clearance mechanism (Radostits et al., 2007). Pneumonia is the inflammation of the pulmonary parenchyma accompanied by inflammation of the bronchioles and often by pleuritis. Pneumonia is multifactorial and caused by combination of infectious agents, with variety of physical and physiological stressors combining to predispose cattle to disease. Mannheimia haemolytica, Pasteurella multocida, Histophilus somni, and Mycoplasma bovis are most common isolates of bovine respiratory tract diseases. The collection of samples to identify the causative organism from lower respiratory tract is particularly difficult. Tracheobronchoscopy is noninvasive technique which is useful for direct visualization of lesions in respiratory tract and collection of bronchoalveolar lavage (BAL). BAL is subjected to cytology, cultural examination, sensitivity tests and polymerase chain reaction (PCR) for early etiological diagnosis and successful treatment. The present study was on the use of tracheobronchoscopy in the etiological diagnosis of bacterial pneumonia in cattle.

\section{MATERIALS AND METHODS}

Cattle that were brought to the large animal medical unit of Teaching Veterinary Clinical Complex (TVCC), Veterinary College and Research Institute, Namakkal with clinical signs of fever, nasal discharge, cough and changes in respiratory characteristics were screened. They were

How to cite this article: Venkatesakumar, E., Vijayakumar, G. Balasubramaniam, G.A. and Rajeswar, J.J. (2020). Tracheobronchoscopic evaluation of bacterial pneumonia in cattle. J. Anim. Res., 10(3): 383-388. Source of Support: None; Conflict of Interest: None 
subjected to detailed clinical examination, haematological examination, serum biochemical analysis, radiography and tracheobronchoscopy for confirmation of pneumonia.

\section{Tracheobronchoscopy}

Tracheobronchoscopy was done in the standing animals without sedation using Olympus ${ }^{\mathrm{TM}}$ [CF type V70L] flexible video endoscope with a diameter of $12.9 \mathrm{~mm}$ and an usable length of $1680 \mathrm{~mm}$. The endoscope was inserted into the ventral nasal meatus and moved forward along the nasal septum up to the region of the pharynx and nasolarynx. Upon reaching the larynx, the endoscope was inserted into the trachea and moved forward to tracheal bifurcation and to bronchial areas. The following parameters were evaluated in each region: mucosal surface, colour (pink, reddened, anaemic), vascularization, oedema, quantity and a description of any secretions (serous, mucous, mucoid, purulent, mucopurulent or blood mixed) as described by Stierschiender et al. (2007).

\section{Bronchoalveolar lavage collection}

Bronchoalveolar lavage (BAL) was collected by advancing endoscope as caudal as possible through the bronchiole branches and wedged at the segmental bronchi. About 180 milliliters of normal saline / phosphate buffer saline (PBS) was infused through the working channel of the endoscope and the same was collected in to mucus extractor using a suction apparatus (Kahl and Hofmann, 1985). BAL fluid was divided into two aliquots and subjected to cytological and cultural examinations.

\section{Bronchoalveolar lavage cytology}

BAL fluid collected for cytological examination was loaded in the WBC counting chamber of haemocytometer under 40x objectives to get the total count of cells (Wilkie and Markham, 1981). Portion of BAL was centrifuged at $900 \times \mathrm{g}(2000 \mathrm{rpm})$ for 10 minutes. The supernatant was decanted and the pellet was resuspended in $0.5 \mathrm{ml}$ of saline and was used to prepare smears. These smears were air dried, fixed in the alcohol and stained with Giemsa stain. Slides were evaluated for cytological and differential count evaluation as per Allen et al. (1992a) and Cadlow (2001).

\section{Bronchoalveolar lavage culture}

BAL fluid collected aseptically for cultural examination was streaked on blood agar, nutrient agar, brain heart infusion (BHI) agar, cetrimide agar, chocolate agar and MacConkey agar for isolation of bacteria. Part of the BAL was also inoculated on Frey's mycoplasma medium and then into Frey's mycoplasma agar for identification of Mycoplasma if any. Culture plates were incubated as per standard methods. Presumptive and definitive identification of pathogens were done by staining characteristics, colony morphology and standard biochemical tests (Barrow and Feltham 1993 and Quinn et al., 1994). The biochemical tests for bacteria were performed using commercial kit (KB003 Hi25 ${ }^{\mathrm{TM}}$ HiMedia, Mumbai).

\section{Polymerase chain reaction}

Polymerase chain reaction (PCR) was performed using Mastermix (2x Taq MasterMix Red dye - Amplicon, USA) with composition of $150 \mathrm{mM}$ Tris $\mathrm{Hcl}(\mathrm{pH} 8.5)$, $40 \mathrm{mM}\left(\mathrm{NH}_{4}\right)_{2} \mathrm{SO}_{4}, 4.0 \mathrm{mM} \mathrm{MgCl}, 0.2 \%$ Tween $20,0.4$ $\mathrm{mM}$ dNTPs, 0.05 units/ $\mu 1$ Taq DNA polymerase, inert red dye and stabilizer and DNA ladder (Bio-basic, USA (100 bp to $1000 \mathrm{bp}$ ) and GeNei, Bangalore (50 bp to 500 $\mathrm{bp})$. Individual colonies for different organisms were resuspended in the nutrient or BHI broth and incubated over night. The broth cultures were utilized for the bacterial DNA extraction using the DNA isolation kit (GeNei, Bangalore) and manual heat and thaw method (Radu et al., 2000). DNA templates were extracted from Pasteurella multocida, Klebsiella pneumoniae and Pseudomonas aeruginosa using DNA isolation kit. PCR identification of $\mathrm{KMT}_{1}$ clone of Pasteurella multocida was done at $460 \mathrm{bp}$ as per Townsend et al. (1998). PCR for Klebsiella pneumoniae was run to identify rpo $B$ gene at $108 \mathrm{bp}$ as per Chander et al. (2011). PCR identification of Pseudomonas aeruginosa was done by amplification of exotoxin A gene at $396 \mathrm{bp}$ as per Khan and Cerniglia (1994). DNA template was extracted by manual heat and thaw method described by Radu et al. (2000). PCR was run using Eco 223 and Eco 455 primers to identify Escherichia coli at 232 bp as per Mohamed et al. (2013). PCR reaction mixture was prepared with DNA templates obtained from bacteria before running in the PCR gel. PCR was run in Bio Rad thermal cycler as per the specifications of individual organisms. After the running the PCR, reaction mixture 
was kept at $4^{\circ} \mathrm{C}$ until running in the gel electrophoresis. The gel electrophoresis (Bio Rad, USA) was conducted with electrified of $80 \mathrm{~V}$ for $45 \mathrm{~min}$. The gel was examined in Gel doc ${ }^{\mathrm{TM}}$ system (Bio Rad, USA) and documented. Positive samples of each organism were utilized for PCR sequencings. The sequencing was undertaken at $\mathrm{M} / \mathrm{s}$. Scigenom laboratories (Cochin, Kerala) and Amnion Biosciences Pvt. Ltd (Sequencing Dept, \#112, Doddenna Industrial Area, 16A Cross, Vishwaneedam Post (D), Bangalore, Karnataka). The obtained nucleotide sequence and the deduced amino acid sequence of organisms isolated were edited using the Editseq programme in the Lasergene package (DNASTAR Inc, Madison, WI, USA), and compared with other reference in Genebank for the homology analysis with the use of MegAlign programme in the same package. Phylogenetic analyses of the amino acid sequence of each organism were performed with the neighbor - joining method using MEGA version 4.0. The bootstrap values were determined from 1000 replicates of the original data.

\section{RESULTS AND DISCUSSION}

Out of 203 cattle screened for various respiratory disorders, 72 cattle were affected with bacterial pneumonia. Twelve apparently healthy cattle were used as control. The predominant clinical signs noticed in cattle with bacterial pneumonia included respiratory distress (97.2\%), increased lung sounds (94.4\%), anorexia (94.4 $\%$ ), pyrexia (91.7\%), nasal discharge (88.9\%), dyspnoea $(86.1 \%)$, muzzle dryness $(86.1 \%)$, tachycardia $(84.7 \%)$, congested mucous membrane (83.3\%), tachypnoea (79.2 $\%)$ and cough (77.8 \%). Radostits et al. (2007), Panousis (2009) and Ozkanlar et al. (2012) observed fever, cough, polypnoea and anorexia in bovine respiratory diseases. Haemato-biochemical evaluation revealed significant increase in mean leukocyte $\left(8.22 \pm 0.35 \times 10^{3} /\right.$ cumm $)$, neutrophil $\left(2.77 \pm 0.14 \times 10^{3} /\right.$ cumm $)$, lymphocyte $(5.23 \pm$ $0.21 \times 10^{3} /$ cumm $)$, monocytes $\left(0.14 \pm 0.01 \times 10^{3} / \mathrm{cumm}\right)$ and eosinophils $\left(0.05 \pm 0.01 \times 10^{3} / \mathrm{cumm}\right)$ counts when compared to healthy control. Clarke et al. (1991) reported increased leukocyte count and neutrophils in bovine bacterial pneumonia.

Radiography of the affected cattle showed increased pulmonary infiltrations. Thirunavukkarasu et al. (2006) and Masseau et al. (2008) reported similar findings in bovine respiratory disorders.
Tracheobronchoscopic examination in cattle with bacterial pneumonia showed mucus, increased fragility of mucosa, petechial haemorrhage / ecchymotic patches, mucoid plugs, mucopurulent exudates with inflammation and swelling of lymphoid follicles in nasopharynx (Fig 1A). Mucus, mucopurulent or mucoid exudates were observed in the trachea (Fig 1B). Severe inflammation, exudates and mucopurulent plug were observed in caudal trachea and carina (Fig 1C), segmental and subsegmental bronchi (Fig 1D \& 1E) of animals with bacterial pneumonia. Franz and Baumgartner (2006) reported reddening, swelling of lymphoid follicles in the roof of pharynx, oedema of arytenoid cartilages and mucus to mucopurulent secretions in cattle with respiratory diseases.

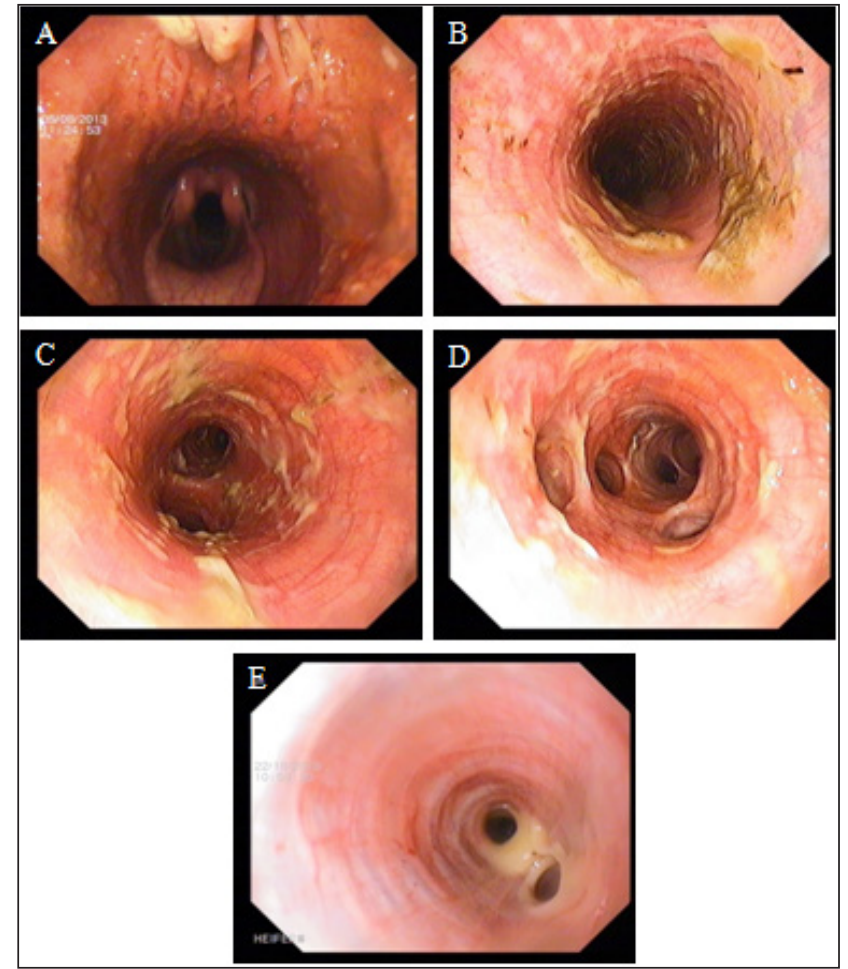

Fig. 1: Tracheobronchoscopic examination in cattle with bacterial pneumonia. (A) Inflammation and swelling of lymphoid follicles of nasopharynx; (B) Inflammation, mucopurulent exudates in trachea; (C) Severe inflammation, mucopurulent exudates caudal trachea and carina; (D) Inflammation and exudates in segmental and subsegmental bronchi; (E) Severe inflammation and mucopurulent plug in subsegmental bronchi

Bronchoalveolar lavage fluid was collected at site of lesions especially in segmental and subsegmental bronchi of cattle with pneumonia. The organisms responsible for 
bacterial pneumonia based on cultural examination of BAL fluid in the present study were Pasteurella multocida (55.95\%), Pseudomonas aeruginosa (16.67\%), Klebsiella pneumoniae (9.52\%) and Escherichia coli (8.33\%). The cultural, gram's staining and biochemical characters of Pasteurella multocida, Pseudomonas aeruginosa, Klebsiella pneumoniae and Escherichia coli were in agreement with Quinn et al. (1994).

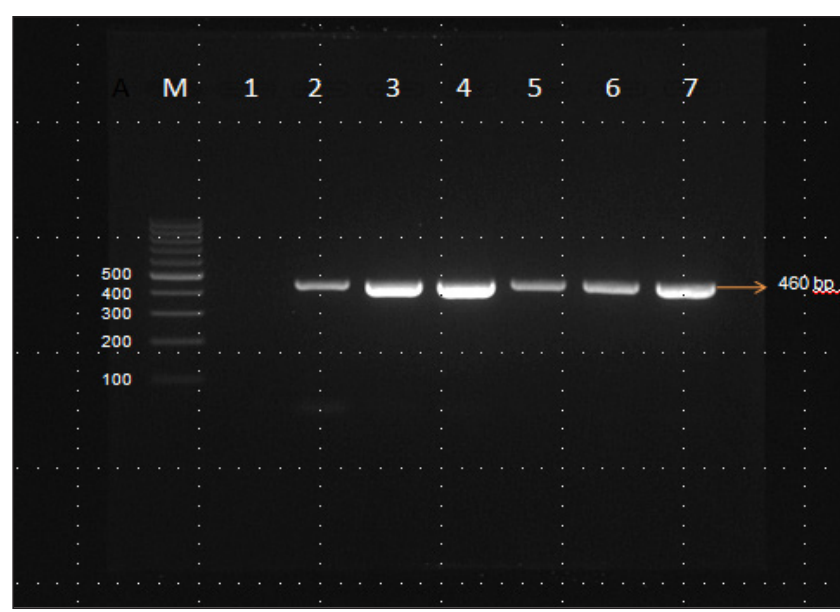

Fig. 2: Agarose gel electrophoresis pattern showing amplified PCR product of Pasteurella multocida with a size of $460 \mathrm{bp}$ in BAL isolates of cattle with pneumonia. M - $100 \mathrm{bp}$ DNA Marker, Lane 1 - Non template control, Lane 2 to 7 - Pasteurella multocida isolates

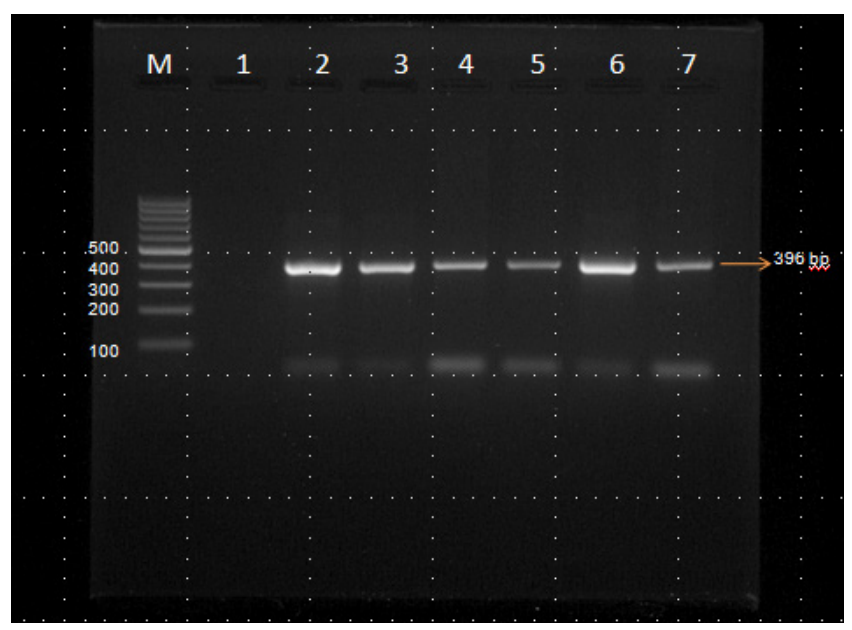

Fig. 3: Agarose gel electrophoresis pattern showing amplified PCR product of Pseudomonas aeruginosa with a size of 396 $\mathrm{bp}$ in BAL isolates of cattle with pneumonia. M - $100 \mathrm{bp}$ DNA Marker, Lane 1 - Non template control, Lane 2 to 7 Pseudomonas aeruginosa isolates
Pasteurella multocida (KMT ${ }_{1}$ clone) at 460 bp (Fig. 2), Klebsiella pneumoniae (rpo B gene) at 108 bp (Fig 3), Pseudomonas aeruginosa (exotoxin A gene) at 396 bp (Fig. 4) and Escherichia coli (Eco 223 and Eco 455 primers) at $232 \mathrm{bp}$ (Fig. 5) were confirmed by polymerase chain reaction and sequencing analysis of PCR products. Pasteurella multocida (Jabeen et al., 2013), Pseudomonas aeruginosa (Franz and Baumgartner, 2006), Klebsiella pneumoniae and Escherichia coli (Aslan et al., 2002) were isolated from cattle with respiratory infections.

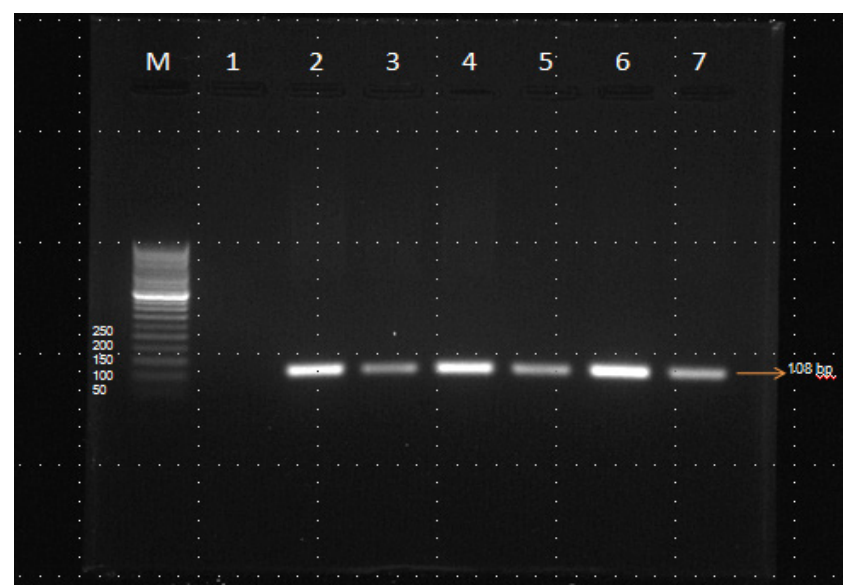

Fig. 4: Agarose gel electrophoresis pattern showing amplified PCR product of Klebsiella pneumoniae with a size of 108 bp in BAL isolates of cattle with pneumonia, M - 50 bp DNA Marker, Lane 1- Non template control, Lane 2 to 7 - Klebsiella pneumoniae isolates

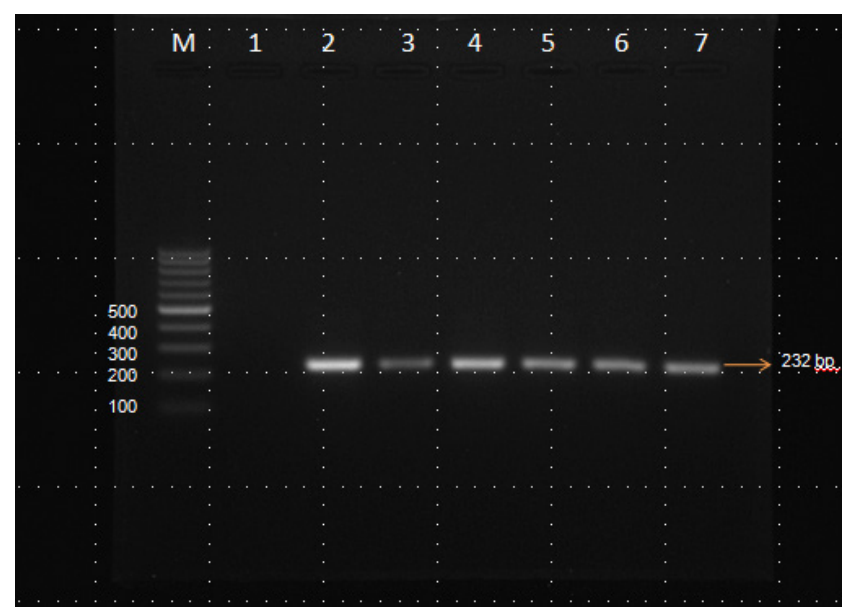

Fig. 5: Agarose gel electrophoresis pattern showing amplified PCR product of Escherichia coli with a size of $232 \mathrm{bp}$ in BAL isolates of cattle with pneumonia. M - 100 bp DNA Marker, Lane 1 - Non template control, Lane 2 to 7 - Escherichia coli isolates 
BAL cytology of cattle with pneumonia revealed increased mean total nucleated cells, macrophages, neutrophils, eosinophils, epithelial cells and plasma cells and decreased mean lymphocytes when compared to respective means of apparently healthy cattle. Thirunavukkarasu et al. (2005) reported similar findings in cattle with respiratory tract diseases. Lay et al. (1986) reported that the bronchoalveolar cells in pneumonia showed an admixture of macrophages, including binucleate and multinucleate forms and neutrophils. In the present study there were clusters of neutrophils with macrophages and binucleated macrophages (Fig. 6A \& 6B).

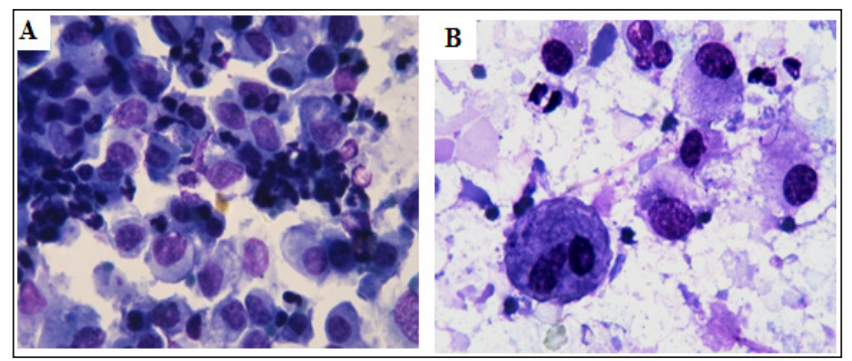

Fig. 6: BAL cytology in cattle with bacterial pneumonia. A, Cluster of neutrophils with macrophages (Giemsa stain x1000); $\mathrm{B}$, Sheet of macrophages including binucleate form with stray neutrophils. (Giemsa stain x1000)

In the present study, tracheobronchoscopy facilitated the direct visualization of lesions in respiratory tract of cattle with bacterial pneumonia and collection of BAL at the site of lesions for cytological and cultural examination.

\section{CONCLUSION}

Tracheobronchoscopy has been one of the best diagnostic aids to visualize the respiratory tract with lesions and also useful in isolation of organisms by collecting BAL. Cultural examination of BAL facilitated the etiological diagnosis of bacterial pneumonia. The total and differential cytological evaluations of BAL are useful in the identification of severity of infection in lung.

\section{ACKNOWLEDGEMENTS}

The authors are thankful to the Dean, Veterinary College and Research Institute, Namakkal and the Director of Clinics, TANUVAS, Chennai for the infrastructure facilities provided during the study.

\section{REFERENCES}

Allen, J.W., Viel, L., Bateman, K.G., Rosendal, S. and Shewen, P.E. 1992. Cytological findings in Bronchoalveolar lavage fluid from feedlot calves: Associations with pulmonary microbial flora. Can. J. Vet. Res., 56: 122-126.

Aslan, V., Maden, M., Erganis, O., Birdane, F.M. and Corlu, M. 2002. Clinical efficacy of florfenicol in the treatment of calf respiratory tract infections. Veterinary Quarterly, 24: 35-39.

Barrow, G.I. and Feltham, R.K.A. 1993. Cowan and Steel's Manual for the identification of Medical bacteria. $3^{\text {rd }}$ edn., Cambridge University Press, New York.

Cadlow, G. 2001. Bronchoalveolar lavage in the investigation of bovine respiratory disease. In Pract., 23: 39-40.

Chander, Y., Ramakrishnan, M.A., Jindal, N., Hanson, K. and Goyal, S.M. 2011. Differentiation of Klebsiella pneumoniae and $K$. oxytoca by multiplex polymerase chain reaction. Intern. J. Appl. Res. Vet. Med., 9: 138-142.

Clarke, C.R., Burrows, G.E. and Ames, T.R. 1991. Therapy of bovine bacterial pneumonia. Vet. Clin. North Am. Food Anim. Pract., 7: 669-94.

Franz, S. and Baumgartner, W. 2006. Diagnostic value of rhinotracheobronchoscopy in cattle with diseases of the respiratory tract. Slovenian Vet. Res., 43: 247-248.

Jabeen, A., Khattak, M., Munir, S., Jamal, Q. and Hussain, M. 2013. Antibiotic susceptibility and molecular analysis of bacterial pathogen Pasteurella multocida isolated from cattle. J. Appl. Pharm. Sci., 3: 106-110.

Kahl, D. and Hofmann, W. 1985. Bronchoscopy in cattle. 1. Techniques. Tierarztliche Umschau, 40: 339-343. Vet. Bull., 55: 563-564.

Khan, A.A. and Cerniglia, C E. 1994. Detection of Pseudomonas aeruginosa from clinical and environmental samples by amplification of the exotoxin A gene using PCR. Appl. Environ. Microbiol., 60: 3739-3745.

Lay, J. C., Slauson, D. O. and Castleman, W. L. 1986. Volumecontrolled Bronchopulmonary lavage of normal and pneumonic calves. Vet. Pathol., 23 : 673-680.

Masseau, I., Fecteau, G., Breton, L., Helie, P., Beauregard, G. and Blond, L. 2008. Radiographic detection of thoracic lesions in adult cows: A retrospective study of 42 cases (1995-2002). Can. Vet. J., 49: 261-267.

Mohamed, A.A.E., Wahba, A.K.A., Faisal, R.A.S.R. and Yousreya, H. M. 2013. Some bacteriological and biochemical studies on subclinical mastitis in buffaloes. New York Sci. J., 6: 71-79.

Ozkanlar. Y., Aktas, M. S., Kaynar, O., Ozkanlar, S., Kirecci, E. and Yildiz, L. 2012. Bovine respiratory disease in naturally infected calves: clinical signs, blood gases and cytokine response. Revue Med. Vet., 163: 123-130. 
Panousis, N. 2009. Dairy calf pneumonia: Effective treatment depends on early and accurate diagnosis. Vet. Glasnik., 63: 177-187.

Quinn, P.J., Carter, M.E., Markey, B.K. and Carter, G.R. 1994. Clinical Vet. Microbiol., Mosby, London, pp. 21-66.

Radostits, O.M., Gay, C., Blood, D.C. and Hinchcliff, K.W. 2007. Veterinary Medicine - A textbook of the diseases of cattle, horses, sheep, pigs and goats, $9^{\text {th }}$ Edn., Saunders, Philadelphia, London, pp. 829-867.

Radu, S., Rusl, G., Ling, O.W., Purwati, E., Mustakim, M. and Lihan, S. 2000. Rapid isolation and detection of Escherichia coli $\mathrm{O} 157: \mathrm{H} 7$ by use of rainbow agar $\mathrm{O} 157^{\mathrm{TM}}$ and PCR assay. Southeast Asian J. Trop. Med. Public Health., 31(1): 77-79.

Stierschiender, M., Franz, S. and Baumgartner, W. 2007. Endoscopic examination of upper respiratory tract and oesophagus in small ruminants: Technique and normal appearance. Vet. J., 173: 101-108.
Thirunavukkarasu, P., Senthilkumar, G., Balachandran, C. and Vasu, K. 2005. Bronchoalveolar lavage fluid (BALF) cytological findings in bovine respiratory disorders (BRD). Indian J. Anim. Res., 39: 137-139.

Thirunavukkarsu, P., Suresh, R.V. and Vasu, K. 2006. Clinical and radiological findings in bovine respiratory disorders. Indian Vet. J., 83: 773-775.

Townsend, K.M., Frost, A.J., Lee, C.W., Papadimitrious, J.M. and Dawkins, H.J.S. 1998. Development of PCR assays for species and type specific identification of Pasteurella multocida isolate. J. Clin. Mirobiol., 36: 1096-1100.

Wilkie, B.N. and Markham, R.J.F. 1981. Bronchoalveolar washing cells and immunoglobulins of clinically normal calves. Am. J. Vet. Res., 42: 241-243. 